\title{
Tetraparesia: an unusual presentation of disseminated tuberculosis
}

\author{
Filipa Quaresma, Margarida Bentes Jesus
}

Department of Internal Medicine, Centro Hospitalar de Lisboa Central, Lisboa, Portugal

\section{Correspondence to} Dr Filipa Quaresma, fquaresma15@gmail.com

Accepted 15 June 2017

\section{SUMMARY}

A 48-year-old man with a 4 months history of asthenia, anorexia, $10 \mathrm{~kg}$ weight loss and 1 month of hematuria and dysuria was admitted to another hospital for sudden muscular weakness. He was found to have areflexic tetraparesis and was referred to our hospital. On admission, he was bradycardic, tachypneic, with flaccid tetraplegia. Laboratory results showed metabolic acidemia, severe hyperkalemia and hyponatremia, acute renal dysfunction and sterile pyuria. After hyperkalemia correction, the neurological symptoms resolved. On the second day, he became febrile and chest radiograph and CT images showed a pulmonary bilateral reticulomicronodular pattern, left hydronephrosis and diffuse bladder wall thickening. Disseminated tuberculosis was considered as diagnosis by the coexistence of this imagiologic alterations and sterile pyuria. Acid-fast test for Mycobacteriumtuberculosis was negative, but the urine culture became positive after 2 weeks.

Antituberculosis treatment was started. One year later, he was asymptomatic and the structural urinary lesions had disappeared.

\section{BACKGROUND}

The authors describe a very uncommon clinical presentation of disseminated tuberculosis, a protean disease which requires a high level of suspicion for a timely diagnosis and correct treatment, allowing for cure without irreversible sequelae.

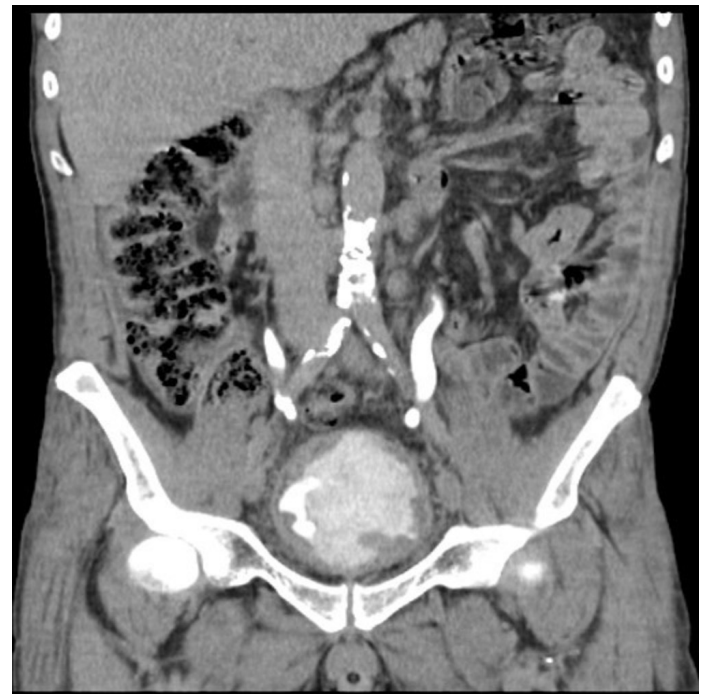

Figure 1 Chest radiograph.

\section{CASE PRESENTATION}

A previously healthy 48-year-old man reported a 4 months history of asthenia, anorexia and weight loss (10 kg); 3 months later hematuria and dysuria appeared.

On the day of admission, he presented to another hospital with sudden muscular weakness. He was admitted with tetraparesia and areflexia. Head and neck CT scan were normal, and he was referred to our hospital for further evaluation. On arrival, 12 hours after the onset of symptoms, he had flaccid tetraplegia with areflexia and no sensory alterations.

\section{INVESTIGATIONS}

Head and spine conventional MRI without contrast were normal; ECG showed completeleft bundle branch blockwith tall and peaked T waves.

Arterial blood gas showed metabolic acidemia (pH 7.29, $\mathrm{PcO}_{2} 23.7 \mathrm{~mm} \mathrm{Hg}, \mathrm{HCO}_{3} 11 \mathrm{mmol} / \mathrm{L}$ ), hyperkalaemia $(8.1 \mathrm{mEq} / \mathrm{L})$, hyponatremia (102 $\mathrm{mEq} / \mathrm{L})$ and hyperlactacidemia $(4.51 \mathrm{mg} / \mathrm{dL})$. Blood tests also showed leukocytosis $\left(21.5 \times 10^{9} / \mathrm{L}\right.$, $92 \%$ neutr), creatinine $3.33 \mathrm{mg} / \mathrm{dL}$, urea $170 \mathrm{mg} /$ $\mathrm{dL}$ andleukocyturia $222 / \mu \mathrm{L}$. Renal ultrasound revealed left hydronephrosis and diffuse bladder wall thickening.

All neurological symptoms resolved on the first day after correction of the hyperkalemia.

The day after admission, he became febrile. Blood and urine cultures were sterile. A chest X-ray showed bilateral micronodular lesions (figure 1). A CT scan revealed a diffuse pulmonary reticulomicronodular pattern, left ureterohydronephrosis and diffuse bladder wall thickening (figures 2 and 3). Cystoscopy revealed reddened and swollen bladder walls, with the presence of abundant sediment; the left meatus was obliterated by oedema. Biopsies were not performed. Serology for HIV was negative.

Tuberculosis was considered the most likely diagnosis; a urinary Ziehl-Neelsen test was negative, but urine culture became positive for Mycobacterium tuberculosis 2 weeks later.

\section{DIFFERENTIAL DIAGNOSIS}

In a patient presenting with hyperkalemia and acute renal dysfunction, imagiologic investigation is important for aetiological investigation since the list of possible causes is extensive. Hydronephrosis points to obstructive/postrenal causes such as neoplastic, lithiasic or infectious. The concomitant bladder thickening make neoplastic and infectious 


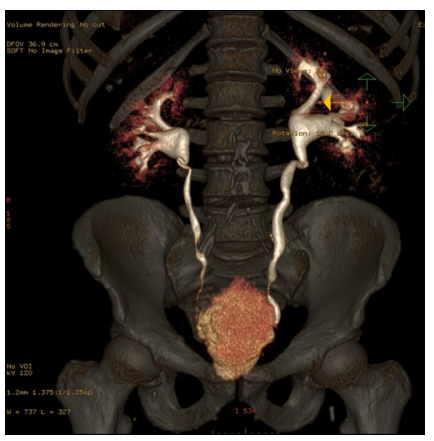

Figure 2 CT scan showing left hydronephrosis and diffuse bladder wall thickening.

causes more probable, and a histological examination would be important to confirm the diagnosis.

In Portugal, where tuberculosis is still a frequent disease, the coexistence of a miliary pulmonary pattern, sterile pyuria, left ureterohydronephrosis and diffuse bladder wall thickening is virtually diagnostic of tuberculosis.

\section{TREATMENT}

The patient was started on antituberculosis (anti-TB) drugs to pulmonary and genitourinary TB treatment.

\section{OUTCOME AND FOLLOW-UP}

Renal function and blood sodium level quickly normalised with rehydration.

Since there was a complete neurological recovery, brain or spine follow-up images/examinations, namely lumbar puncture or MRI, were not performed. Because of the sudden resolution, it was admitted that the neurological alterations occurred in the context of hyperkalemia due to acute renal injury, as has been described in a few case reports. ${ }^{1-3}$

He maintained anti-TB treatment for 6 months and remained asymptomatic with weight gain. Further evaluation with CT scan and cystoscopy, 1 year after presentation, showed progressive recovery with no structural alterations.

\section{DISCUSSION}

$\mathrm{TB}$ is one of the main causes of mortality from infectious diseases worldwide, especially in developing countries, and about one-third of the world's population has latent tuberculosis, according to the WHO 2015 report. $^{4}$

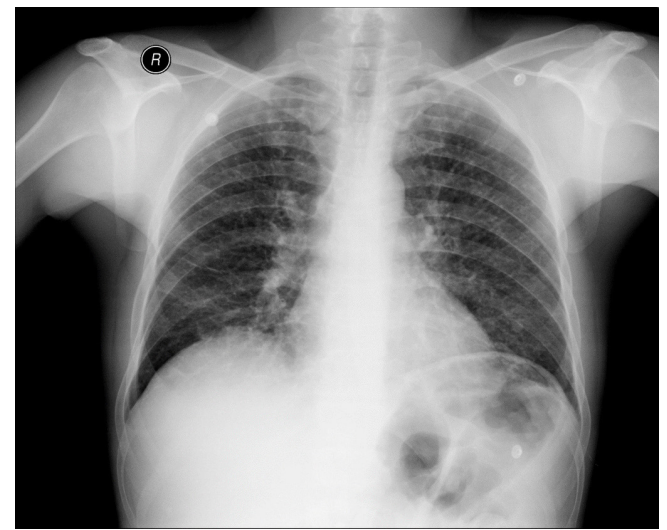

Figure 3 CT scan showing left hydronephrosis and diffuse bladder wall thickening (reconstruction).
Genitourinary TB is a relative common form of extrapulmonary $\mathrm{TB},{ }^{5}$ often underdiagnosed because of its variable and insidious course. A high level of suspicion is important to avoid a delayed diagnosis which can result in organ dysfunction, irreversible sequelae and death. ${ }^{67}$

Urinary TB is usually secondary to hematogenous spread from pulmonary or disseminated $\mathrm{TB}^{7}$; prolonged steroid use or immunosuppressive therapy may increase the risk of reactivation of latent foci. ${ }^{8}$ Symptoms vary with the organ affected, and the disease course may be indolent and asymptomatic but with progressive renal dysfunction and structural deformities. $^{9} 10$

Urine culture gives the definitive diagnosis, taking up to 8 weeks to become positive and with up to $20 \%$ of false negative results. ${ }^{11}$ Molecular methods, as polymerase chain reaction (not done on our patient), give faster results and has been proved to be sensitive and specific, although some false negatives occur because of urinary inhibitory substances. ${ }^{610}$

Anti-TB therapy is recommended for at least 6 months; surgery may be needed for structural deformities. ${ }^{7}$

We present this case for its peculiar presentation and to the best of our knowledge, there is no other description of a presentation from genitourinary $\mathrm{TB}$ as this one in the literature. However, we could not fully explain the marked increase in potassium levels and the reason for the severe acute renal failure, neither its rapid reversion even before starting tuberculostatic treatment. This case also highlights the importance of a timely diagnosis to avoid sequelae of genitourinary TB.

\section{Learning points}

- Urinary tuberculosis has an indolent and unspecific course which may lead to delayed diagnosis and long-term sequelae.

- Correct and early treatment is effective and avoids sequelae.

- Although rarely, severe hyperkalemia can cause ascending weakness with hyporeflexia.

Contributors The two authors were involved with the patient case and the diagnosis. Both considered the case relevant to publication and collaborated doing the manuscript draft and its review, reaching this submitted version.

Competing interests None declared.

\section{Patient consent Obtained.}

Provenance and peer review Not commissioned; externally peer reviewed.

(C) BMJ Publishing Group Ltd (unless otherwise stated in the text of the article) 2017. All rights reserved. No commercial use is permitted unless otherwise expressly granted.

\section{REFERENCES}

1 McCarty M, Jagoda A, Fairweather P. Hyperkalemic ascending paralysis. Ann Emerg Med 1998:32:104-7.

2 Maury E, Lemant J, Dussaule JC, et al. A reversible paralysis. Lancet 2002;360:1660.

3 Tapiawala S, Badve SV, More N, et al. Severe muscle weakness due to hyperkalemia. J Assoc Physicians India 2004;52:505-6.

4 WHO. Global Tuberculosis Report 2015. 20th edn. Geneva: World Health Organization, 2015. http://www.who.int/tb/publications/global_report/en/ (accessed 19 Jun 2016).

5 Navarro-Vilasaró M, Font B, Sala M, et al. Micobacteriosis genitourinaria: estudio retrospectivo de 45 casos en un hospital general. Enferm Infecc Microbiol Clin 2008;26:540-5.

6 Wise GJ, Marella VK. Genitourinary manifestations of tuberculosis. Urol Clin North Am 2003;30:111-21

7 Fillion A, Koutlidis N, Froissart A, et al. [Investigation and management of genitourinary tuberculosis]. Rev Med Interne 2014;35:808-14. 
8 Zajaczkowski T. Genitourinary tuberculosis: historical and basic science review: past and present. Cent European J Urol 2012;65:182-7.

9 Kapoor R, Ansari MS, Mandhani A, et al. Clinical presentation and diagnostic approach in cases of genitourinary tuberculosis. Indian J Urol 2008;24:401-5.
10 Cek M, Lenk $S$, Naber $K G$, et al. EAU guidelines for the management of genitourinary tuberculosis. Eur Urol 2005;48:353-62.

11 Sourial MW, Brimo F, Horn R, et al. Genitourinary tuberculosis in North America: a rare clinical entity. Can Urol Assoc J 2015:9:484-9.

Copyright 2017 BMJ Publishing Group. All rights reserved. For permission to reuse any of this content visit

http://group.bmj.com/group/rights-licensing/permissions.

BMJ Case Report Fellows may re-use this article for personal use and teaching without any further permission.

Become a Fellow of BMJ Case Reports today and you can:

- Submit as many cases as you like

- Enjoy fast sympathetic peer review and rapid publication of accepted articles

Access all the published articles

Re-use any of the published material for personal use and teaching without further permission

For information on Institutional Fellowships contact consortiasales@bmjgroup.com

Visit casereports.bmj.com for more articles like this and to become a Fellow 